Bulletin d'Histoire Contemporaine de

I'Espagne

$54 \mid 2020$

Les espaces du politique dans l'Espagne du Trienio liberal (1820-1823)

\title{
Claude Morange (1937-2019)
}

Emilio La Parra y Universidad de Alicante

\section{(2) OpenEdition \\ Journals}

Edición electrónica

URL: http://journals.openedition.org/bhce/3367

DOI: $10.4000 /$ bhce.3367

ISSN: 1968-3723

Editor

Presses Universitaires de Provence

Edición impresa

Fecha de publicación: 1 enero 2020

ISSN: 0987-4135

Referencia electrónica

Emilio La Parra y Universidad de Alicante, « Claude Morange (1937-2019) », Bulletin d'Histoire

Contemporaine de l'Espagne [En línea], 54 | 2020, Publicado el 01 julio 2020, consultado el 31 diciembre

2020. URL : http://journals.openedition.org/bhce/3367 ; DOI : https://doi.org/10.4000/bhce.3367

Este documento fue generado automáticamente el 31 diciembre 2020.

Bulletin d'histoire contemporaine de l'Espagne 


\section{Claude Morange (1937-2019)}

\section{Emilio La Parra y Universidad de Alicante}

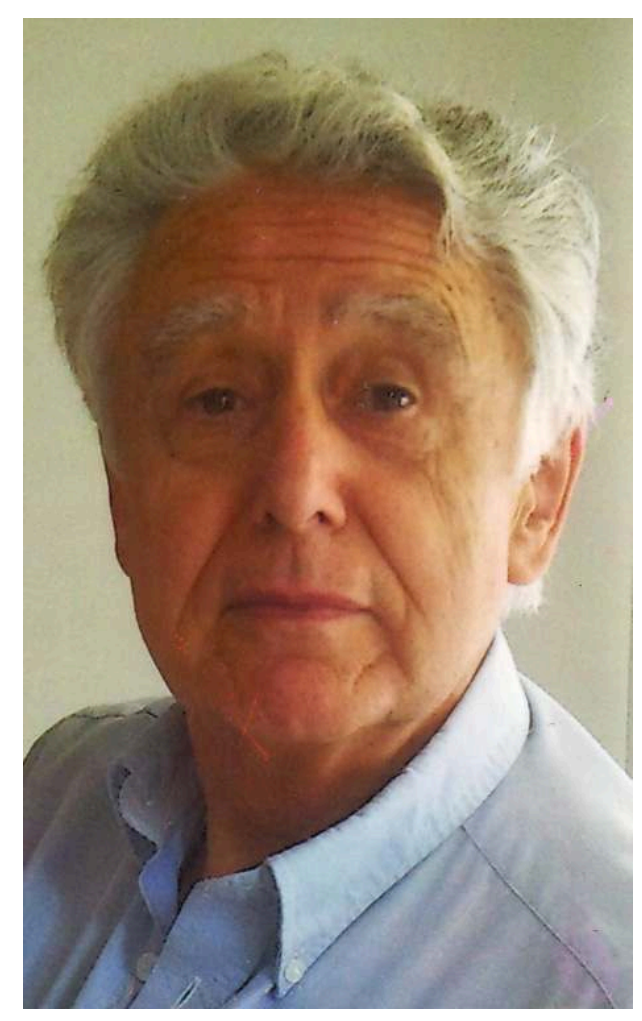

\section{(C) M.Morange}

2 El 4 de diciembre de 2019 nos conmovió la noticia del fallecimiento de Claude Morange, antiguo alumno de la École Normale Supérieure de Saint-Cloud, Maître de Conférences de la Université de la Sorbonne Nouvelle Paris 3, donde desempeñó la mayor parte de su vida profesional.

3 Morange ha sido un profesor muy apreciado por sus alumnos (he tenido ocasión de escuchar elogios directamente de varios de ellos, así como de sus colegas docentes, caso este último poco frecuente en el ámbito universitario) y un investigador valorado en 
muy alto grado. No conozco una crítica negativa de su producción historiográfica, antes al contrario, son unánimes los elogios. Esto tiene una explicación evidente: Morange ha sido un historiador riguroso y culto, y ha publicado únicamente aquello que tenía bien elaborado. Puede que haya contribuido asimismo su carácter. Inteligente y agudo en el análisis como pocas personas, honesto intelectualmente $y$, en consecuencia, consciente -quizá hasta el exceso- de sus limitaciones. Con frecuencia calificó sus publicaciones de simples hipótesis de trabajo o aportación de materiales, destinadas a ayudar a otros a profundizar en el campo de estudio en cuestión, y ni siquiera se decidió a presentar como tesis de doctorado su trabajo -impresionante, por extensión y profundidad- sobre Sebastián de Miñano. Ya jubilado, en 2002 publicó en la Universidad de Salamanca una parte de su investigación sobre este inquieto personaje con sorprendente título, neologismo incluido: Paleobiografía (1779-1819) del "Pobrecito Holgazán" Sebastián de Miñano y Bedoya. El libro, al igual que el resto de los de Morange, abunda en análisis y en datos, y como él mismo declaró en su prólogo, está construido más en archivos que en bibliotecas, durante muchos años de investigación ("demasiados, suelen reprocharme algunos amigos", afirmaba). Era y sigue siendo, sin lugar a dudas, la mejor biografía de Miñano, aunque no abarca toda su vida. No obstante, Morange puntualizaba en el prólogo: "esto no es una biografía: solo proporciona materiales para ella."

4 Morange ha sido un maestro para muchos. Su nombre forma parte de un excelente grupo de hispanistas franceses dedicado al estudio del tránsito del siglo XVIII al XIX, dicho de otra forma, al tiempo de la Ilustración y el primer liberalismo. Estos hispanistas, cuyos nombres omito ahora porque la nómina es nutrida y no deseo incurrir en olvidos, se han ganado en Francia con todo merecimiento la condición de historiadores, superando la etiqueta de "civilisationnistes" con que se les tildó en los medios académicos. A partir de los años ochenta del siglo pasado fue considerable su influencia sobre historiadores españoles, y sobre los aspirantes a serlo. De su legado cabe resaltar dos elementos. Primero: demostraron que el tránsito del siglo XVIII al XIX constituye un tiempo histórico con rasgos propios, merecedor de la mayor atención, con lo cual contribuyeron a romper el corsé establecido por la división académica española entre los departamentos universitarios de Historia Moderna y Contemporánea, de funestos resultados. Segundo: enseñaron que la interdisciplinariedad proporcionaba excelentes resultados y era una vía idónea para la renovación de la historiografía española, vehemente aspiración esta al sur de los Pirineos tras la desaparición del asfixiante régimen franquista.

5 Circunscrito cronológicamente a los cien años que comprenden la segunda mitad del XVIII y la primera del siglo siguiente, Claude Morange se ha preocupado por muchas cuestiones: el alcance de la Ilustración española, su relación con Francia, la Guerra de la Independencia y sus protagonistas, la construcción del Estado liberal, la contrarrevolución en la época fernandina, los proyectos constitucionales alternativos al de 1812, la prensa y la opinión pública, la naturaleza política del primer liberalismo español... Sus obras sobre estas materias son referentes, como lo corroboran las frecuentes citas que de ellas realizan de continuo los especialistas en trabajos monográficos o de síntesis.

6 El ejercicio del oficio de historiador de Claude Morange se ha caracterizado por el análisis detallado, exhaustivo, del objeto de estudio (muchas veces en el tiempo corto) a partir de una sólida base empírica, pues como él mismo se definió, fue un historiador de 
archivo; la formulación de interpretaciones, siempre agudas y muchas veces novedosas; y la exposición de una explicación fundamentada en el método comparativo. Modelo de esta manera de hacer historia, y guía utilísima para el análisis en profundidad de un acontecimiento, es una de sus obras principales: Una conspiración fallida y una Constitución nonnata (1819) (Madrid, 2006). Este libro ha renovado el conocimiento de la tradicionalmente denominada "conspiración del Palmar", uno de los movimientos subversivos del tiempo conocido como Sexenio Absolutista. Además de hacer una nueva propuesta, muy bien fundamentada y convincente, sobre los intentos insurreccionales contra la política de Fernando VII en este periodo, calificados impropiamente, según Morange, de "pronunciamientos", ofrece claves para una interpretación de los proyectos alternativos al modelo basado en la Constitución de 1812 .

7 Rasgo muy relevante de la actividad como investigador de Claude Morange es su capacidad para dar a conocer documentación relevante, que era desconocida o había pasado inadvertida a los historiadores. Tal es el caso de los documentos sobre los que funda su obra antes mencionada, que él bautiza como "plan Beitia", o los escritos de Juan Olavarría, objeto asimismo de análisis por parte de Morange en un extenso volumen, o las inéditas Cartas amistosas y políticas al rey de España de Luis Gutiérrez, el autor de la famosa novela Cornelia Boroquia, dadas a conocer en una recopilación de artículos publicada en 1990 por el Instituto de Cultura Juan Gil-Albert de Alicante. En todos estos casos, Morange sitúa en el primer plano el documento y se limita a atribuirse el cometido de simple presentador del mismo. El resultado final, sin embargo, no responde a este propósito, porque la introducción con que Morange acompaña invariablemente este tipo de trabajos suele ser extensísima y constituye una monografía con suficiente entidad como para ser publicada como libro. En definitiva, en todos los casos prima el análisis. Morange ha estado muy lejos de la tentación positivista.

8 La última obra de Morange, realmente monumental, ha aparecido en Ediciones de la Universidad de Salamanca poco antes de su fallecimiento. Se trata de un estudio en profundidad del periódico El Censor, uno de los más importantes en España durante el Trienio Liberal, tiempo de extraordinario florecimiento de la prensa, cuya influencia posterior fue muy acusada, pues está en el origen doctrinal del Partido Moderado, dominante durante buena parte del reinado de Isabel II. Una vez más, Morange hace gala de su capacidad de análisis, de su gran erudición, de su habilidad para plantear problemas relevantes, y para ofrecer explicaciones novedosas sobre el liberalismo español. El Censor había sido objeto de atención por parte de Morange desde hacía décadas, pues uno de sus fundadores fue Sebastián de Miñano, objeto preferente de su investigación inicial. Nadie conocía mejor que Morange este periódico tan determinante en el liberalismo español, pero salvo algún texto aislado, no se había decidido a publicar el estudio completo que tenía desde hace tiempo si no finalizado, si muy desarrollado. Finalmente, gracias al impulso de Ricardo Robledo, director de Ediciones Universidad de Salamanca, disponemos de la obra tan esperada y necesaria. Pero fiel a sí mismo hasta el final, Claude Morange afirma en la introducción del volumen que "si de este libro solo debiera conservarse algo, serían sin duda los índices [del periódico], porque podrán ahorrar a futuros investigadores muchas horas de trabajo largo y fastidioso." Como siempre, resta relevancia a su estudio sobre el surgimiento y características del periódico y el análisis de su riquísimo y complejo contenido, todo lo cual ocupa algo más de 500 páginas. 
9 Claude Morange es quizá más conocido en España que en Francia, excepción hecha, naturalmente, de los hispanistas de este último país. Tal vez esto se deba a que la mayor parte de sus trabajos ha sido publicada en castellano, en su mayoría redactados directamente en esta lengua por el autor, por cierto de forma correctísima. Por esta circunstancia, y porque mantuvo amistad con un buen número de historiadores españoles, podríamos afirmar que con su fallecimiento hemos perdido a un gran historiador español, aunque sería más correcto decir europeo, pues eso fue Claude Morange, un ciudadano europeo comprometido intelectual, política y sindicalmente con la sociedad de su tiempo. 